\title{
New challenge for physicians: are visual hallucinations and psychiatric disorder the same?
}

\author{
Cristina Sicorschi ${ }^{1}$, Laura del Riego Ardizzone ${ }^{1}$ \\ 1 Family Medicine trainees, Hospital Clinico San Carlos, Madrid, Spain
}

Nowadays medicine is experiencing changes constantly, and sometimes is hard to keep updated with all the information we receive. On top of that, population is changing too: it is getting older.

For a correct medical practice and an appropriate care we have to be familiar with disorders we didn't study at Medical School, diseases that older people have greater risk to develop. Patients expect the best knowledge and medical treatment from us, and there is no time to stay in the comfort zone. It is important to keep our minds open and listen to what our patients tell us: medicine is not an exact science, so same symptoms mean different diagnosis.

Sometimes we can learn more from the people that come to our consultations than from the books. We just have to listen carefully to what the patient is telling us and select the most important information. An example of that would be the symptoms a patient reported us in the General Practice consultation. She mentioned visual hallucinations and we immediately related it to psychiatric illness. Actually, her mental status was normal [1], and a complete neurologic evaluation was performed. She kept reporting the same symptoms and finally was referred to Ophthalmology Department, where she was diagnosed of Charles Bonnet's syndrome [2].

Charles Bonnet was a naturalist and philosophical writer, born in Geneva. In 1760 he described a condition, now called after him, in which visual hallucinations occur in psychologically normal people. His grandfather, who was nearly blind from cataracts, had it. And now, two centuries later, this clinical condition is more common than generally appreciated. Sometimes it's misdiagnosed as psychosis or early dementia, because this phenomenon is not a well-recognized disorder by clinicians. One reason could be that we often tend to go to the most frequent diagnosis and stay reluctant to changes in our daily practice. As our population is getting older, we must be more aware of the increasing number of other secondary illnesses. Very frequently patients fear physicians will associate their visual hallucinations with mental disease, like we did, so they fail to report their symptoms. Older age and worse visual acuity are risk factors, so in the near future more and more patients will be diagnosed for sure.

Finally, this approach should be taken in consideration next time we have a patient in our consultation. In this case, visual hallucinations decreased significantly patient's quality of life, and reassurance was 
really important. Sometimes is all that the patients really need; however, treatment should be offered as well [3.4]. Even partial relief is good relief. This way we can be sure we do what we have to do, that is, providing healthcare to our general population.

\section{References}

1. Teunisse RJ, Cruysberg JR, Hoefnagels WH, et al. visual hallucinations in psychologically normal people: Charles Bonnet's syndrome. Lancet 1996; 347: 794-7; http://dx.doi.org/10.1016/S01406736(96)90869-7

2. Fernandez A, Lichstein G, Vieweg WV. The Charles Bonnet syndrome: a review. J Nerv Ment Dis 1997; 185: 195-200; http://dx.doi.org/10.1097/00005053-199703000-00009

3. Coletti Moja M, Milano E, Gasverde S, et al. Olanzapine therapy in hallucinatory visions related to Bonnet síndrome. Neurol Sci 2005; 26:168-70; http://dx.doi.org/10.1007/s10072-005-0455-0

4. Jacob A, Prasad S, Boggild M, Chandratre S. Charles Bonnet syndrome- elderly people and visual hallucinations. BMJ 2004; 328: 1552; http://dx.doi.org/10.1136/bmj.328.7455.1552 